Article

\title{
A New Index for Measuring Uncertainty Due to the COVID-19 Pandemic
}

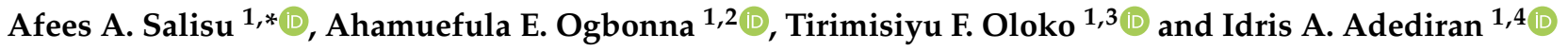 \\ 1 Centre for Econometric \& Allied Research, University of Ibadan, Ibadan 900001, Nigeria; \\ ogbonnaephraim@yahoo.com (A.E.O.); olokotrimicy@yahoo.com (T.F.O.); meetadediran@gmail.com (I.A.A.) \\ 2 Department of Statistics, University of Ibadan, Ibadan 900001, Nigeria \\ 3 Department of Economics, University of Ibadan, Ibadan 900001, Nigeria \\ 4 Department of Economics, Obafemi Awolowo University, Ile-Ife 220282, Nigeria \\ * Correspondence: aa.salisu@cear.org.ng; Tel.: +234-803-471-1769
}

Citation: Salisu, A.A.; Ogbonna,

A.E.; Oloko, T.F.; Adediran, I.A. A

New Index for Measuring

Uncertainty Due to the COVID-19

Pandemic. Sustainability 2021, 13,

3212. https://doi.org/10.3390/

su13063212

Academic Editor: John Rennie Short

Received: 14 February 2021

Accepted: 10 March 2021

Published: 15 March 2021

Publisher's Note: MDPI stays neutral with regard to jurisdictional claims in published maps and institutional affiliations.

Copyright: (c) 2021 by the authors. Licensee MDPI, Basel, Switzerland. This article is an open access article distributed under the terms and conditions of the Creative Commons Attribution (CC BY) license (https:/ / creativecommons.org/licenses/by/ $4.0 /)$.

\begin{abstract}
This study contributes to the emerging literature offering alternative measures of uncertainty due to the COVID-19 pandemic. We combine both news-and macro-based trends to construct an index. The former involves the use of Google trends with plausible variants of words used to capture the pandemic, which are combined using principal components analysis to develop a news-based index. For the macro-based index, we identify global factors such as oil price, stock price, Dollar index, commodity index and gold price, and thereafter we obtain the macro-based uncertainty using variants of stochastic volatility models estimated with Bayesian techniques and using a dynamic factor model. Consequently, the new (composite) index is constructed by combining the news- and macro-based indexes using principal components analysis. Our empirical applications of the index to the stock return predictability of the countries hit worst by the pandemic confirm the superiority of the composite index over the existing news-based index in both the in-sample and out-of-sample forecast horizons. Our results are also robust to forecast horizons and competing model choices.
\end{abstract}

Keywords: COVID-19 pandemic; common correlated effects; heterogeneous panel; uncertainty

\section{Introduction}

The emergence of the COVID-19 pandemic arguably fosters higher global socioeconomic panics and uncertainties [1-3]. While the effects of uncertainties due to the COVID-19 pandemic on macroeconomic indicators, such as economic growth and inflation rate, may manifest with some lags, its effects on financial markets are evident (see, for example, [3-21]). For instance, [5] explains that the sanitary crisis enhances the S\&P 500 realized volatility. The authors of [4] find that both the daily growth in both total confirmed cases and total cases of death caused by COVID-19 have significant negative effects on stock returns across all companies. The authors of [10] report that the number of COVID-19 pandemic cases per million has significant negative effects on global financial markets, while [6] also indicated that stock markets responded negatively to the growth in COVID19 confirmed cases. Meanwhile, [15] notes the COVID-19 fractal contagion effects on the stock market fizzle over the medium- and long-term. This position is also supported by [20], which finds that the negative impact of COVID-19 on emerging stock markets has gradually fallen, and begun to taper off in mid-April.

The huge literature on the impact of the pandemic notwithstanding, extant studies have largely relied on information-based indexes/indicators, such as news about the COVID-19 disease or health in general. For instance, news about COVID-19 new cases of infection and fatality was used by $[4-6,10,15,19,20,22,23]$. This is also used by [3], in the generation of the COVID-19-induced global fear index for the analysis of uncertainty due to COVID-19 (see also, [19]). Meanwhile, evidence shows that virtually all global economic 
indicators experienced structural shocks during the COVID-19 pandemic, which suggests that an indirect source of uncertainty due to the COVID-19 pandemic exists (see [9]). We hypothesize that the extension of the existing COVID-19-induced indexes to accommodate global macro-variables is likely to improve model precision.

Thus, this study proposes a new index for measuring uncertainty due to the COVID-19 pandemic, which allows for both news and global economic indicators. Thus, rather than relying singly on COVID-19-related news, we develop a composite index that combines both COVID-19-related news and uncertainty due to global economic indicators (such as the global oil price (see [23-29]), gold price, stock price (see [27,30,31]), commodity prices and exchange rate). Related studies such as [19] and [20] accounted for the role of global factors independently of the COVID-19-induced uncertainty index. With this approach, the role of changes in global factors is accounted for, and not their associated uncertainty, which is a major concern for financial investors (see [32]). Similarly, this approach causes the plurality of the associated regressors of the model, which will result in biased results, especially when the sample size is small. With the new index proposed in this study, uncertainties due to the COVID-19 pandemic are wholly captured, while the parsimony of the regression model is maintained.

We apply the newly proposed (composite) uncertainty due to the COVID-19 pandemic index to the stock returns predictability of the twenty economies that were worst-hit by COVID-19, to empirically compare our proposed index with other related indexes. The choice of stock market for empirical application is motivated by its wide accessibility and high exposure to systematic and unsystematic risks [33-35]. Apparently, this study examines the stock returns predictability of uncertainty due to the COVID-19 pandemic, using a new uncertainty due to the COVID-19 pandemic index. This innovation is similar to the work of [19], which develops and assesses the significance of health news as a predictor of stock returns. Meanwhile, a negative relationship may be expected between this COVID-19 pandemic predictor and stock market returns, as higher uncertainty in the stock market due to the COVID-19 pandemic is expected to cause a reduction in stock market returns. For robustness purposes, we further compare the effect of the COVID-19induced uncertainty index developed in this study with that of the Chicago Board Options Exchange (CBOE) volatility index (VIX). As a way of showing the relevance of accounting for heterogeneity, we compare our predictive model with the conventional pooled ordinary least-squares regression model. We also assess the robustness of our new index to different forecast horizons.

Following this introduction section, the remaining sections are structured as follows. Section 2 explains the procedures for the computation of the new uncertainty due to the COVID-19 index. Empirical application of the new index was presented in Section 3. This consists of data issues, a methodological framework and the presentation and discussion of results. Section 4 deals with robustness checks and analyses, while Section 5 concludes the paper.

\section{Materials and Methods}

In this study, we develop a new index for measuring uncertainty due to the COVID-19 pandemic. This new index is composite index of the news-based uncertainty due to the COVID-19 index and macroeconomic-indicators-based uncertainty due to the COVID-19 index. This section is sub-divided into four sub-sections. The first sub-section explains the computation of the news-based index, the second sub-section describes the process for computing the macro-based index, the third sub-section describes the new index proposed in this study and the fourth sub-section presents the methodology used in the application of the new index to the predictability of stock returns. We provide a summarized framework of the study in Figure 1. 


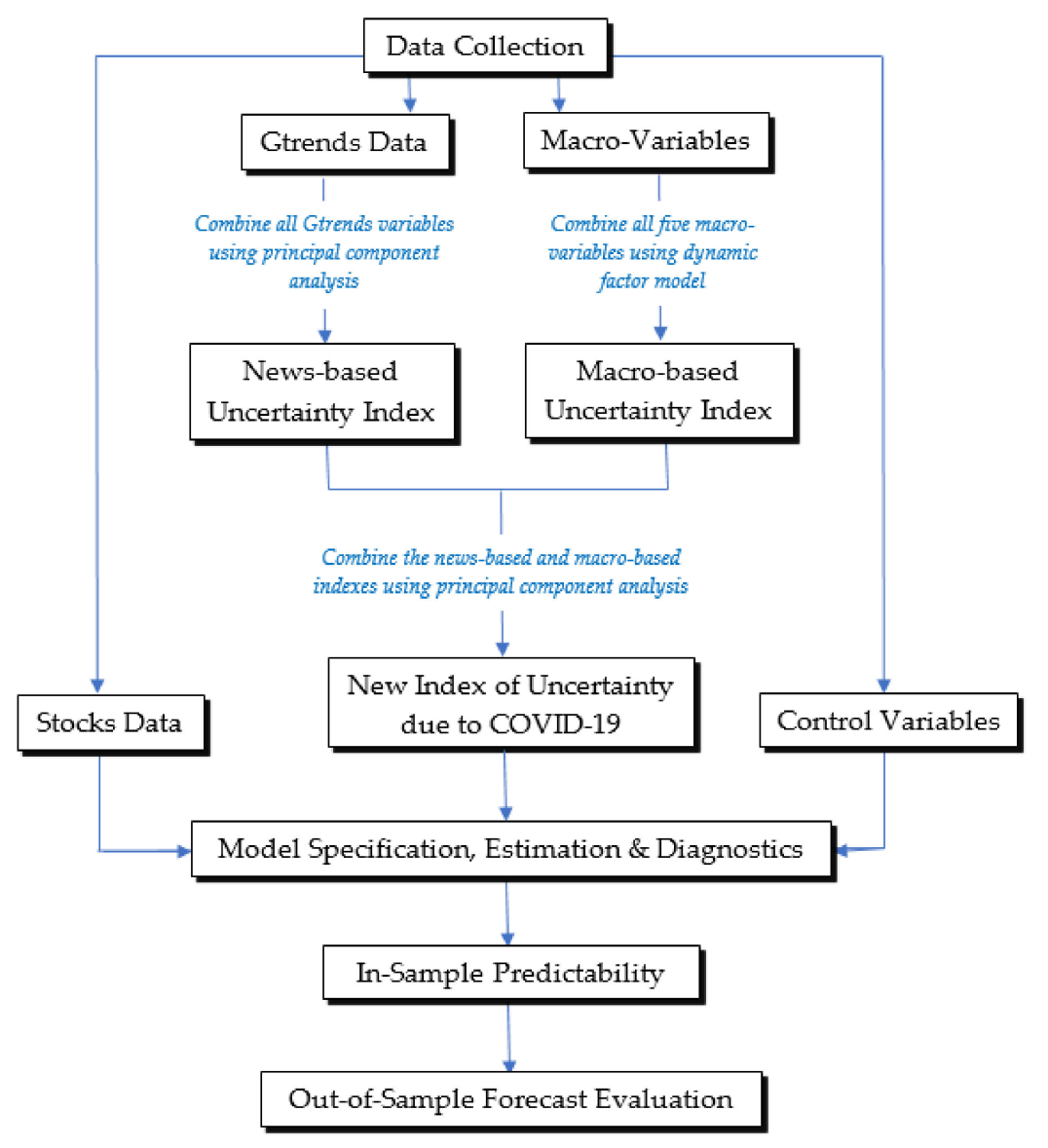

Figure 1. Diagrammatic framework of the study.

\subsection{The News-Based Index}

We draw from the big data archive of Google trends and construct a news-based index that gives a measure of the uncertainty induced by the COVID-19 pandemic. The considered period spanned 1 January 2020 to 21 July 2020, covering the days before and after the World Health Organisation (WHO) declaration of COVID-19 as a pandemic on 11th March, 2020. The news-based index seeks to measure the accessibility of information (awareness) about the pandemic, given the rate at which it spread across the countries of the globe. Consequently, we extract worldwide Google search volumes relating to different keywords that have become more frequently used as a result of the pandemic. These keywords were carefully thought out, as they revolve around searches relating to the COVID-19 pandemic. The keywords and/or phrases include: "Coronavirus", "nCov2", "Severe acute respiratory syndrome”, “Covid - 19", “COVID-19", “COVID”, “Pandemic COVID-19”, “COVID-19 Pandemic", "Pandemic", "Vaccine", “COVID Vaccine", "COVID-19 and Stock", and "Stock Market". The resulting search volume variables were subsequently combined in a principal components' analysis, to create a news-index-COVID-19-Induced Uncertainty: Stock tracker (hereafter, ciustk.news) - by generating the first principal component factor. This bears some resemblance to the index in [22], except for the inclusion of stock worded searches. The inclusion of stocks-related keywords was informed by the need to give the proposed index a stock perspective, hence its consideration as a stock tracker. The index is then normalized using

$$
\text { ciustk.news }_{\text {scaled }}=(b-a) \times \frac{\text { ciustk.news }_{\text {unscaled }}-\min \left(\text { ciustk.news }_{\text {unscaled }}\right)}{\max \left(\text { ciustk.news }_{\text {unscaled }}\right)-\min \left(\text { ciustk.news }_{\text {unscaled }}\right)}+a
$$

where $a$ and $b$ indicate the least and highest values for our index. Therefore, our index takes values between $a=1$ (the lowest level of uncertainty) and $b=100$ (the highest level of 
uncertainty). Although several variants of the index were generated, the employed index showed more predictability for stocks. The comparisons were only meant to ascertain the index variant that is data-supported to track stocks. The results are, therefore, not reported here.

\subsection{The Macro-Based Index}

Having considered a news-based index to ascertain the vulnerability of the stocks of the twenty countries worst hit by the COVID-19 pandemic, we also consider a macrovariable-based index of uncertainty. We consider five global macro-variables that have a close linkage with equity markets. These include gold price, oil price, commodity index, dollar index and stock price. We extract the volatilities inherent to each of these macrovariables using the stochastic volatility models. We employ the seven (7) variants of the stochastic volatility (SV) model (see [36] for a detailed description of the method) in an empirical search for the optimal model for the corresponding macro-variables. These variants differ by the assumption imposed on the log-volatility and/or model, and are briefly defined as follows: SV incorporates a stationary AR(1) log-volatility process; SV-2 is an SV model with AR(2) log-volatility process; SV-J is an SV with a jump component in the price equation; SV-L is SV with leverage; SV-M is SV with log-volatility included as a covariate in the price equation; SV-MA is SV model with MA(1) observation error; while SV-t is an SV model with $t$ innovation. For each of the macro-variables considered, the seven stochastic volatility model variants were empirically compared to ascertain the optimal model that is supported by data, from which an associated uncertainty (in the form of volatility) is extracted. The result of the comparison is present in Table 1, which shows the optimal model selected for the corresponding macro-variable: SV-MA (Gold and WTI), SV-t (Commodity Index), SV (Dollar Index), and SV-M (S\&P500); judging by the maximum marginal likelihood values in each macro-variable case. We subsequently employ the dynamic factor model to generate a single macro-based index of uncertainty and scaled same to take values between 1 and 100, as in the case of the news-based index. The scaled macro-based index of uncertainty (hereafter, ciustk.mac) is defined as

$$
\text { ciustk.mac }_{\text {scaled }}=(b-a) \times \frac{\text { ciustk.mac }_{\text {unscaled }}-\min \left(\text { ciustk.mac }_{\text {unscaled }}\right)}{\max \left(\text { ciustk.mac }_{\text {unscaled }}\right)-\min \left(\text { ciustk.mac }_{\text {unscaled }}\right)}+a
$$

with $a$ and $b$ as previously defined, such that ciustk.mac lies between $a=1$ (the lowest level of uncertainty) and $b=100$ (the highest level of uncertainty).

Table 1. Marginal Likelihood of contending stochastic volatility (SV) model variants.

\begin{tabular}{cccccc}
\hline Model & Gold Price & Oil Price & $\begin{array}{c}\text { Commodity } \\
\text { Index }\end{array}$ & Dollar Index & Stock Price \\
\hline Scheme 240. & -240.9 & -427.1 & -253.8 & -90.0 & -291.3 \\
SV_2 & -241.0 & -427.4 & -254.3 & -90.6 & -291.2 \\
SV_J & -242.2 & -427.4 & -254.3 & -93.5 & -290.8 \\
SV_L & -245.6 & -433.9 & -258.3 & -93.4 & -296.5 \\
SV_M & -241.7 & -428.8 & -254.7 & -91.0 & -291.1 \\
SV_MA & -240.8 & -426.9 & -253.4 & -90.5 & -291.3 \\
SV_t & -240.9 & - & -252.0 & -90.6 & - \\
\hline Optimal Model & SV_MA & SV_MA & SV_t & SV & SV_M \\
\hline
\end{tabular}

Note: SV incorporates a stationary AR(1) log-volatility process; SV-2 is SV model with AR(2) log-volatility process; SV-J is SV with a jump component in the price equation; SV-L is SV with leverage; SV-M is SV with log-volatility included as a covaria11te in the price equation; SV-MA is SV model with MA(1) observation error; while SV-t is $\mathrm{SV}$ model with $\mathrm{t}$ innovation. The models designated with (-) indicates no convergence.

\subsection{The New Index for Measuring Uncertainty Due to COVID-19 Pandemic}

We employ the principal component analysis, combining both news-based and macro-based indexes, to generate a composite index of COVID-19-induced uncertainty 
(ciustk.cmp). The new (composite) index is expected to be more informative, given that it includes both news- and macro-dynamics. It is scaled to range between 0 and 100 , as a similitude of the indexes described earlier. The new (composite) index is used to ascertain the vulnerability of stocks to the COVID-19 pandemic.

We consider here the daily stock prices of the twenty countries worst-hit by the COVID19 pandemic as of 22 July 2020 . The list of countries by the number of confirmed cases, recorded as of 22 July 2020 was extracted from the John Hopkins University database, asit has consistently and promptly produced COVID-19 records of events as they occur. The list of countries, in decreasing order of confirmed cases is: US, Brazil, India, Russia, Peru, Chile, Mexico, Spain, UK, South Africa, Iran, Pakistan, Italy, Saudi Arabia, Turkey, Germany, Bangladesh, France, Colombia, Canada, Qatar, Argentina. We also consider Google search volumes relating to the pandemic, as well as some control variables, such as global oil price (West Texas Intermediate (WTI)), exchange rate (with US dollar being the reference currency) and Chicago Board Options Exchange (CBOE) volatility index (VIX). The stock price data of the twenty worst hit countries, the country specific exchange rate as well as the five macro-variables (gold price, oil price (WTI), commodity index, dollar index and stocks (S\&P500) were all taken from www.investing.com [37]; the pandemic-related worldwide Google search volumes were extracted from the Google Trends database; VIX was sourced from Fred Louis database. All the series were extracted from the respective databases on 22 July 2020. Given the unavailable and/or incomplete stock price data for Iran (11th worst hit) and Bangladesh (17th worst hit) on the investing.com [37] website, the 21st (Qatar) and 22nd (Argentina) worst hit-countries on the rank list were included to make the number of countries considered twenty. Consequently, the twenty countries considered in this study include Argentina, Brazil, Canada, Chile, Colombia, France, Germany, India, Italy, Mexico, Pakistan, Peru, Qatar, Russia, South Africa, Saudi Arabia, Spain, Turkey, the UK and the US. We present a summary of these variables in Table 2.

The average returns of the top twenty worst-hit countries by the COVID-19 pandemic over the investigated period is observed to be negative, except in the case of the US, which has an average of 0.0001 . The returns on stock in Brazil appear to be the most volatile, while those of Qatar were found to be the least volatile. All the stocks are found to be negatively skewed and leptokurtic, which conforms with the characteristic feature that returns are usually not normally distributed. The exchange rates are denominated in US dollar per country's domestic currency, showing that about a quarter of the top twenty worst-hit countries have currency values that are stronger than the US dollar. These exchange rates are mostly positively skewed (except in Canada, Pakistan, Peru, Qatar, Saudi-Arabia and the UK) and platykurtic (except in the case of the UK). On the global independent variables, ciustk.news, ciustk.cmp and wti are negatively skewed, while vix and ciustk.mac are positively skewed, and ciustk.news and ciustk.cmp exhibit platykurtic feature, while the peaks in ciustk.mac, wti and vix are higher than normal, exhibiting excess kurtosis (that is, they are leptokurtic). Among the indexes, ciustk.cmp is placed between the least and most volatile uncertainty indexes, which corresponds to ciustk.mac and ciustk.news. 
Table 2. Summary Statistics.

\begin{tabular}{|c|c|c|c|c|c|c|c|c|c|c|c|c|}
\hline & Mean & SD & Min. & Max. & Skewness & Kurtosis & Mean & SD & Min & Max & Skewness & Kurtosis \\
\hline & \multicolumn{6}{|c|}{ Stock Returns } & \multicolumn{6}{|c|}{ Exchange Rate } \\
\hline Argentina & -0.0004 & 0.0404 & -0.1596 & 0.1187 & -0.7919 & 5.5888 & 0.015 & 0.001 & 0.014 & 0.017 & 0.064 & 1.622 \\
\hline Brazil & -0.0030 & 0.0444 & -0.1943 & 0.1516 & -1.1057 & 8.3183 & 0.204 & 0.023 & 0.170 & 0.248 & 0.505 & 1.818 \\
\hline Canada & -0.0005 & 0.0278 & -0.1333 & 0.1180 & -0.9434 & 11.8686 & 0.734 & 0.021 & 0.689 & 0.771 & -0.046 & 1.963 \\
\hline Chile & -0.0019 & 0.0319 & -0.1674 & 0.0816 & -1.4908 & 10.2145 & 0.001 & 0.000 & 0.001 & 0.001 & 0.071 & 1.568 \\
\hline Colombia & -0.0041 & 0.0437 & -0.2190 & 0.1594 & -1.3138 & 12.4686 & 0.000 & 0.000 & 0.000 & 0.000 & 0.231 & 1.833 \\
\hline France & -0.0012 & 0.0247 & -0.1315 & 0.0806 & -1.2034 & 9.0450 & 1.105 & 0.019 & 1.069 & 1.145 & 0.170 & 1.902 \\
\hline Germany & -0.0005 & 0.0242 & -0.1334 & 0.0990 & -1.0600 & 10.8425 & 1.105 & 0.019 & 1.069 & 1.145 & 0.170 & 1.902 \\
\hline India & -0.0017 & 0.0224 & -0.1374 & 0.0631 & -1.9005 & 14.0439 & 0.013 & 0.000 & 0.013 & 0.014 & 0.635 & 1.727 \\
\hline Italy & -0.0012 & 0.0275 & -0.1878 & 0.0828 & -2.6413 & 19.2188 & 1.105 & 0.019 & 1.069 & 1.145 & 0.170 & 1.902 \\
\hline Mexico & -0.0026 & 0.0295 & -0.1118 & 0.0686 & -0.7194 & 4.9219 & 0.046 & 0.005 & 0.039 & 0.054 & 0.450 & 1.590 \\
\hline Pakistan & -0.0022 & 0.0208 & -0.0779 & 0.0493 & -0.9942 & 5.5772 & 0.006 & 0.000 & 0.006 & 0.006 & -0.030 & 1.474 \\
\hline Peru & -0.0029 & 0.0312 & -0.1356 & 0.1018 & -0.8587 & 6.7586 & 0.292 & 0.006 & 0.280 & 0.303 & -0.140 & 2.106 \\
\hline Qatar & -0.0009 & 0.0149 & -0.0718 & 0.0430 & -1.0439 & 9.5622 & 0.274 & 0.001 & 0.272 & 0.275 & -0.507 & 1.572 \\
\hline Russia & -0.0012 & 0.0279 & -0.1186 & 0.0837 & -1.0569 & 7.3341 & 0.014 & 0.001 & 0.012 & 0.016 & 0.294 & 1.944 \\
\hline South Africa & -0.0011 & 0.0174 & -0.0890 & 0.0643 & -1.2703 & 10.6315 & 0.060 & 0.006 & 0.052 & 0.071 & 0.414 & 1.800 \\
\hline Saudi Arabia & -0.0003 & 0.0247 & -0.0948 & 0.0723 & -1.0855 & 7.0813 & 0.266 & 0.000 & 0.266 & 0.267 & -0.903 & 2.664 \\
\hline Spain & -0.0017 & 0.0262 & -0.1547 & 0.0751 & -1.5283 & 11.5221 & 1.105 & 0.019 & 1.069 & 1.145 & 0.170 & 1.902 \\
\hline UK & -0.0014 & 0.0224 & -0.1150 & 0.0849 & -1.0183 & 8.8013 & 1.260 & 0.036 & 1.149 & 1.320 & -0.422 & 3.174 \\
\hline \multirow[t]{2}{*}{ US } & 0.0001 & 0.0277 & -0.1292 & 0.0899 & -0.7214 & 8.0750 & 1.000 & 0.000 & 1.000 & 1.000 & . & . \\
\hline & & & & & & & \multicolumn{6}{|c|}{ Global Variables } \\
\hline ciustk.news & & & & & & & 43.44 & 28.80 & 2.13 & 100.00 & -0.10 & 1.84 \\
\hline ciustk.mac & & & & & & & 51.11 & 17.15 & 1.00 & 100.00 & 0.23 & 4.35 \\
\hline ciustk.cmp & & & & & & & 56.22 & 21.01 & 0.00 & 100.00 & -0.26 & 2.81 \\
\hline$w t i$ & & & & & & & 37.29 & 14.78 & -37.63 & 63.27 & -0.82 & 6.08 \\
\hline vix & & & & & & & 32.22 & 15.61 & 12.10 & 82.69 & 0.97 & 3.85 \\
\hline
\end{tabular}

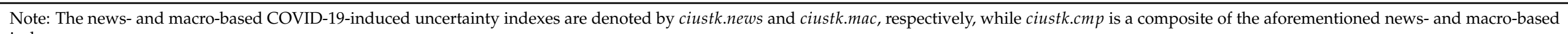
indexes. 
Three bivariate plots of major stocks of twenty worst-hit countries by COVID-19 and three variants of the index of COVID-19-induced uncertainty (news-based, macro-based and composite of both) are displayed in Figures 2-4. The figures show the dynamics in terms of the movement of each pair of stock prices and COVID-19-induced uncertainty between 2 January and 17 July 2020. A notable co-movement is clearly observed between stocks and COVID-19-induced uncertainty across all twenty countries considered, especially as stocks appears to respond to the World Health Organisation (WHO) declaration of COVID-19 as a global pandemic on 3 March 2020. Prior to this period, the stocks of these countries were relatively stable; however, upon the WHO's declaration, stock prices peaked and establish a new equilibrium at a higher level than the period before the declaration. This suggests some form of structural shift in the movement pattern. Hence, the incorporation of structural breaks into the predictive model, as well as other salient data features, are likely to improve the model predictive performance (see [24,38]; among others), especially regarding the news-based index. An equally crucial observation from the figures is that the composite and macro-based indexes moved more closely with the stock prices, further justifying the contribution of this study to improve the news-based predictive model with relevant macroeconomic information.
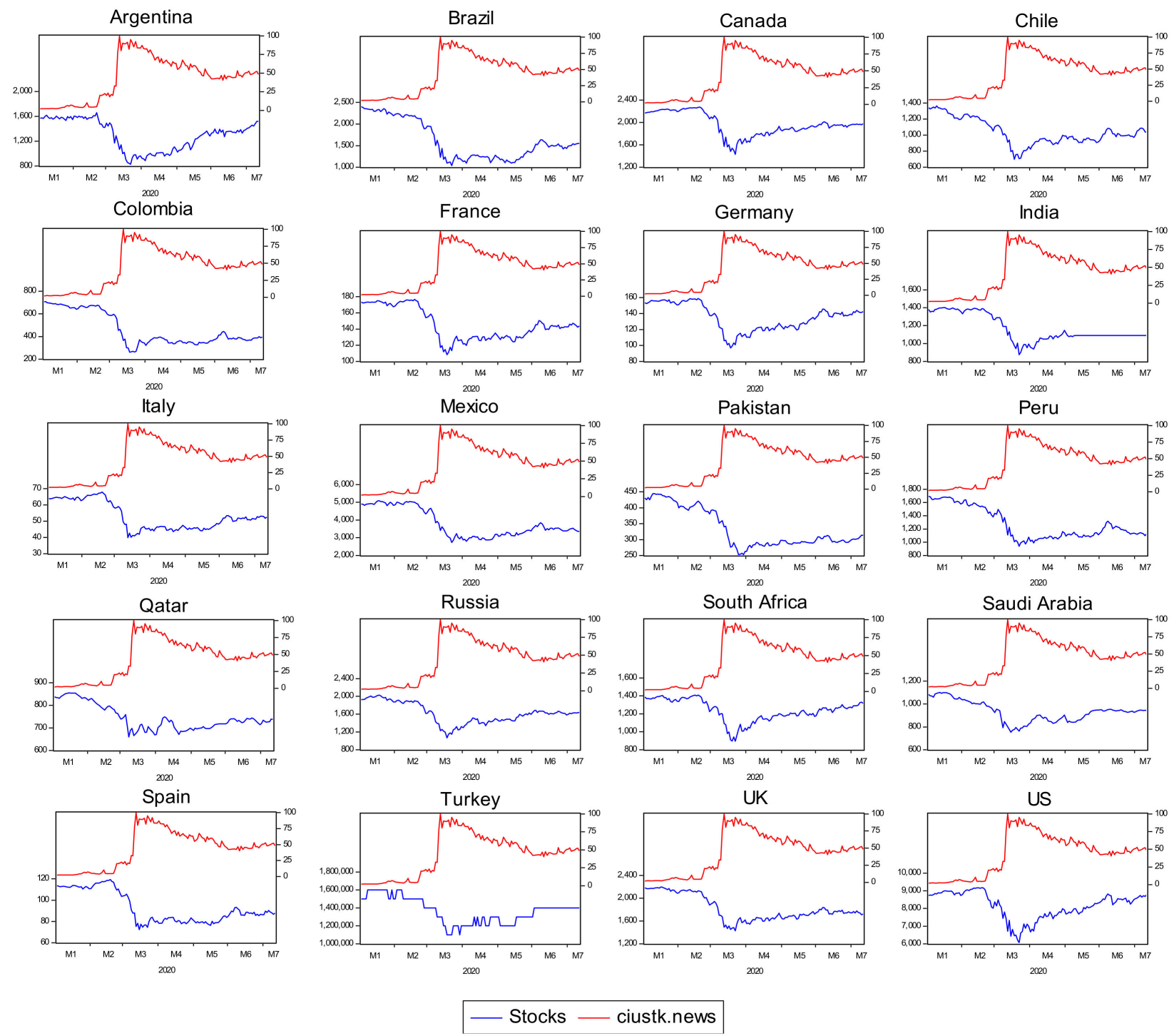

Figure 2. Bivariate plot of major stocks of twenty worst-hit countries by COVID-19 and the news-based index of COVID-19induced uncertainties. 

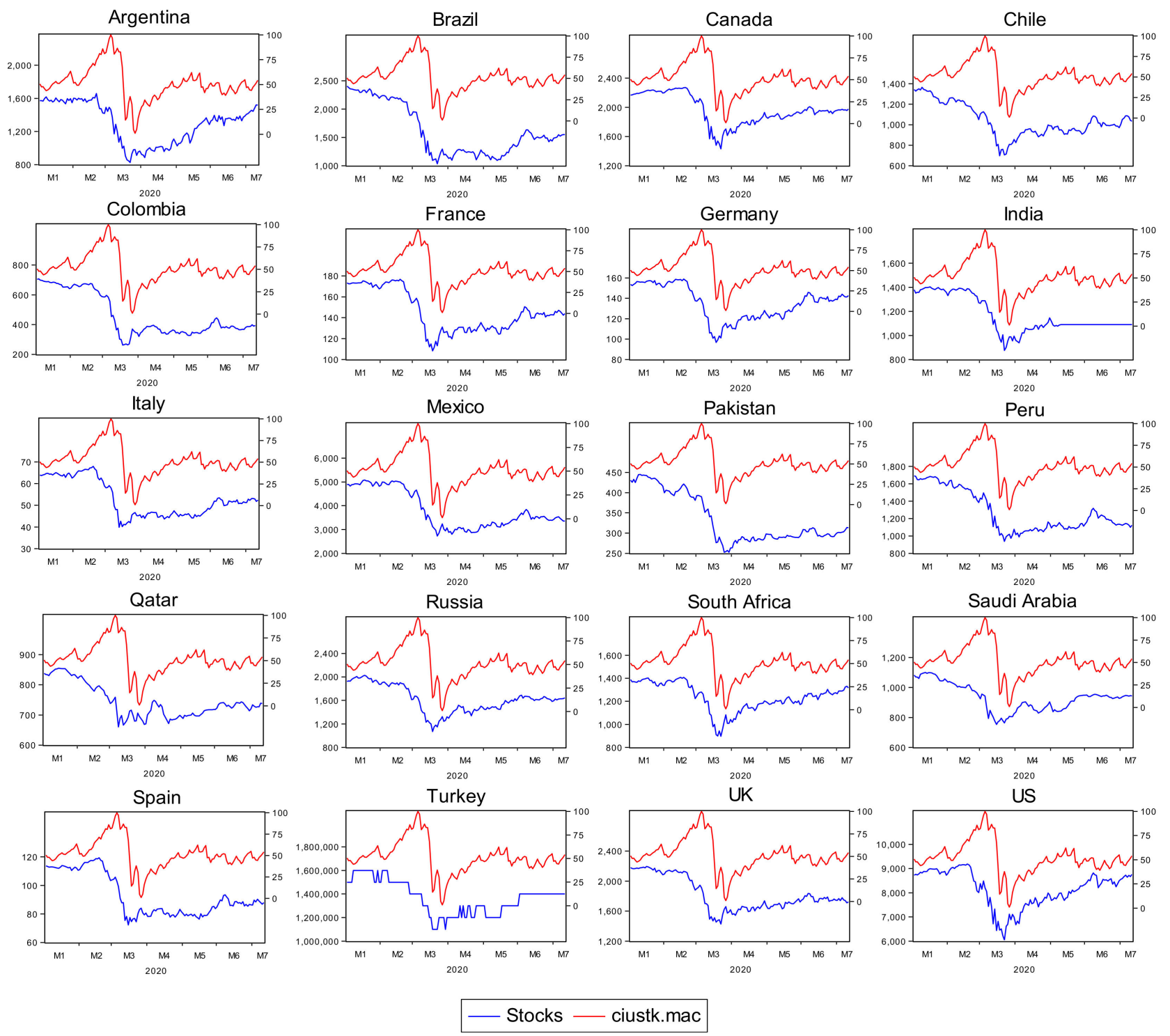

Figure 3. Bivariate plot of major stocks of twenty worst-hit countries by COVID-19 and the macro-based index of COVID19-induced uncertainties.

\subsection{Methodology}

We construct a predictive model that is similar to the works of $[3,19]$ and hinges on the risk-return hypothesis, which assumes that financial assets can produce higher returns only if the investor will accept a higher possibility of losses. Put differently, the hypothesis implies that financial assets that at least retain their value in the face of risks/uncertainties can serve as good hedges. Another important feature of the model is that it allows for heterogeneity in the intercept and slope coefficients, since the considered stock returns may respond differently to the uncertainty information. In other words, stock markets may be more resilient or vulnerable than the others. In addition to accounting for observed (common and country-specific) factors, the predictive model also allows for unobserved common factors, such as global supply and demand shocks, which are capable of influencing the behavior of stock markets. We follow the estimation procedure of $[30,39-41]$ to estimate the model. We acknowledge $[42,43]$ for the dynamic panel a with dynamic common correlated effects estimation program. The predictive model is specified in Equations (3) and (4), as follows 


$$
r_{i t}=\left\{\begin{array}{l}
\alpha_{i}+\sum_{j=1}^{p} \delta_{i} \text { ciust }_{i, t-j}+e_{i t} ; \quad \text { without control } \\
\alpha_{i}+\sum_{j=1}^{p} \delta_{i} \text { ciust }_{i, t-j}+Z_{i t}{ }^{\prime} \phi_{i}+e_{i t} ; \quad \text { with control } \\
\quad e_{i t}=\lambda_{i} f_{t}+u_{i t} ; i=1,2, \ldots, N \text { and } t=1,2, \ldots, T
\end{array}\right.
$$

where $r_{i t}$ is stock returns and is defined as $100 \times \log \left(P_{i t} / P_{i, t-1}\right)$ with $P_{i t}$ representing the stock prices for the $i^{\text {th }}$ country at the $t^{\text {th }}$ period; ciust $k_{i t}$ an index that gives a measure of uncertainty due to the COVID-19 pandemic (news-based and composite) while vectors of control variables involving oil price and exchange rate returns are represented as $Z_{i t}$. Additionally, $\alpha_{i}$ is the heterogenous intercept that varies across the cross-sectional units; $\delta_{i}$ represents the slope coefficients associated with ciust $k_{i t}$ the corresponding vector of parameters for the control variables is symbolized as $\phi_{i}$, and they all vary across the cross-sectional units. In the last equation $e_{i t}$ is described as a composite error term, which comprises an unobserved common factor loading $\left(f_{t}\right)$, a heterogeneous factor loading $\left(\lambda_{i}\right)$ and the remainder error term $\left(u_{i t}\right)$. We also allow for up to five lags $(j=1,2, \ldots, 5)$ to account for day-of-the-week effect that often characterizes most daily frequency financial series (see also $[19,29,44]$. Our interest is basically in the predictive feature of the generated index ciust $k_{i t}$ that is measured by the $\delta_{i}$ in Equation (3). We test the null hypothesis of no predictability $-H_{0}: \delta_{i}=0$ against a mutually exclusively alternative hypothesis of predictability- $H_{0}: \delta_{i} \neq 0$ (this could be positive or negative, depending on the degree of independence). We also consider a model that does not account for heterogeneity-the pooled ordinary least squares (POLS) regression model.
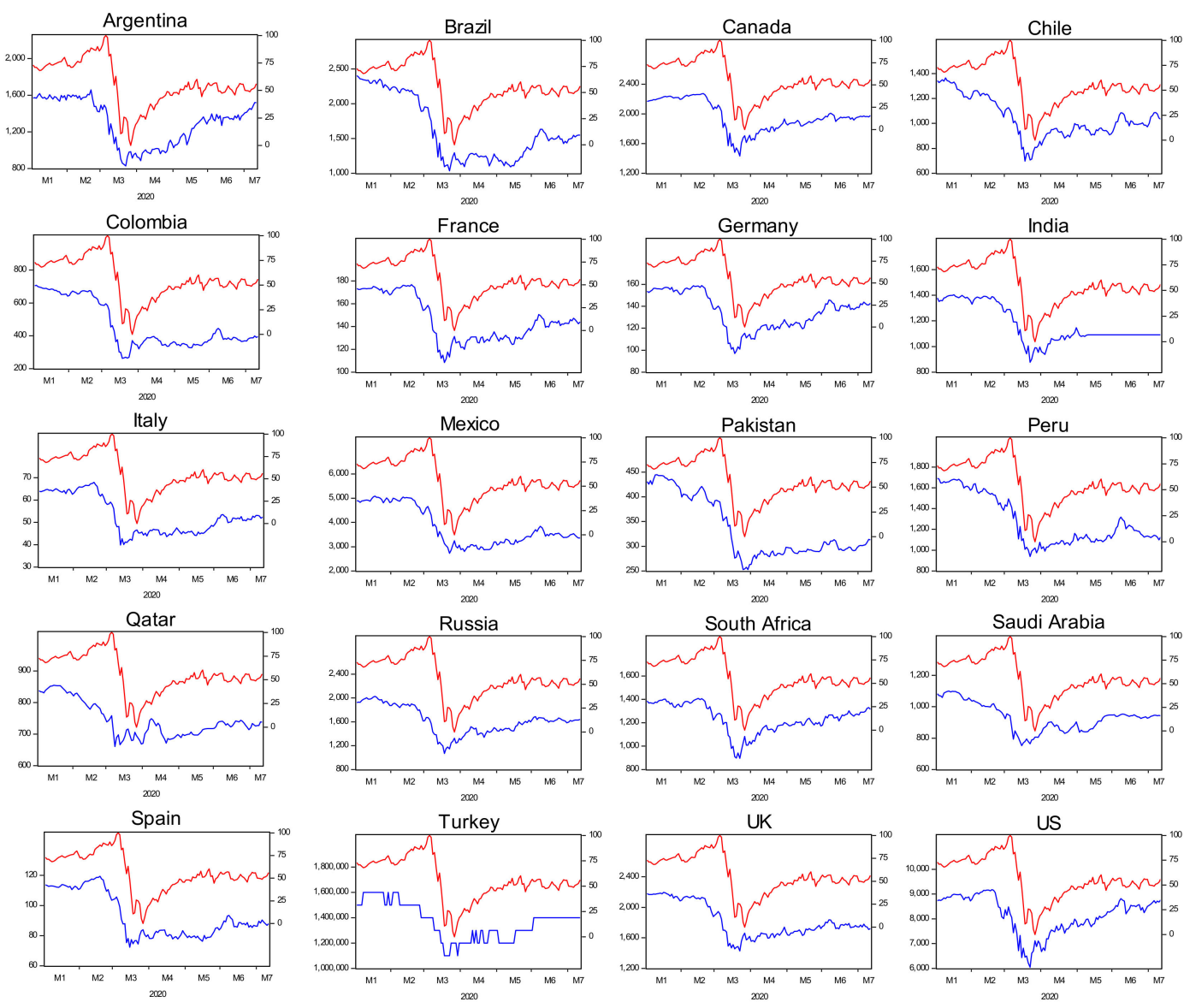

- Stocks _ ciustk_composite

Figure 4. Bivariate plot of major stocks of twenty worst-hit countries by COVID-19 and the composite index of COVID-19induced uncertainties. 
For the purpose of forecast evaluation, we also employ the Clark and West [31] (C-W) test, which compares the predictive accuracy of two competing models, such as comparing the new composite index with the baseline news-based predictive model or the POLS regression model, in addition to comparisons of each of the models with and without accounting for the roles of macroeconomic variables and structural breaks in the data. Unlike the C-T test (see [45]), we use the C-W test to establish the difference between the forecast errors of the competing models, to see whether it is statistically significant. The underlying procedure for the $\mathrm{C}-\mathrm{W}$ test involves working with Equation (6)

$$
\hat{f}_{t+k}=\left(r_{t+k}-\hat{r}_{1 t, t+k}\right)^{2}-\left[\left(r_{t+k}-\hat{r}_{2 t, t+k}\right)^{2}-\left(\hat{r}_{1 t, t+k}-\hat{r}_{2 t, t+k}\right)^{2}\right]
$$

where $k$ is the forecast period, $\left(r_{t+k}-\hat{r}_{1 t, t+k}\right)^{2}$ is the squared error for the restricted model (for instance, the model without control or the news-based model) $\left(r_{t+k}-\hat{r}_{2 t, t+k}\right)^{2}$ is the squared error for the unrestricted model (for example, the model that controls for macroeconomic variables or the composite index-based model), and $\left(\hat{r}_{1 t, t+k}-\hat{r}_{2 t, t+k}\right)^{2}$ is the adjusted squared error introduced by the $\mathrm{C}-\mathrm{W}$ test to correct for noise associated with the extended model's forecast. Thus, the sample average of $\hat{f}_{t+k}$ can be expressed as $M S E_{1}-\left(M S E_{2}\right.$ - adj.), and each term is computed as in Equations (7)-(9) as follows

$$
\begin{aligned}
& M S E_{1}=P^{-1} \sum\left(r_{t+k}-\hat{r}_{1 t, t+k}\right)^{2} \\
& M S E_{2}=P^{-1} \sum\left(r_{t+k}-\hat{r}_{2 t, t+k}\right)^{2} \\
& \text { adj. }=P^{-1} \sum\left(\hat{r}_{1 t, t+k}-\hat{r}_{2 t, t+k}\right)^{2}
\end{aligned}
$$

where $P$ is the number of predictions required to compute the averages. To implement the C-W test for equality of forecast performance between any of the competing models, we regress $\hat{f}_{t+k}$ on a constant, and the resulting t-statistic for a zero coefficient helps to draw the necessary inference. Since the null hypothesis of the C-W tests for equality of mean square errors, the alternative hypothesis implies otherwise. Hence, we reject the null hypothesis if the test statistic realized is greater than +1.282 (for a one-sided 0.10 test) or + 1.645 (for a one-sided 0.05 test).

\section{Results}

This section deals with the presentation and discussion of the results of our empirical analyses. The section discusses the empirical results of the COVID-19-induced uncertainty predictability of stock returns of the twenty (20) worst-hit countries by the COVID-19 pandemic and the results for the evaluation of our predictive model. This is followed by a stand-alone section on robustness, which deals with sensitivity checks, where the results from our empirical model (using the proposed composite COVID-19-induced uncertainty index) is compared with the results obtainable using news-based and macro-based models, and an alternative volatility index by Chicago Board Options Exchange (CBOE).

\subsection{Main Results}

The empirical results from our heterogeneous static and dynamic common-correlated effects (CCE) estimators are presented in Tables 3 and 4; where Table 3 presents the results for the predictability of news-based and news-macro composite COVID-19-induced uncertainty for stock market returns of the 20 worst-hit countries by COVID-19. These are examined with and without control variables, as previously noted. As suggested by the graphs presented in Figure 1, we account for structural breaks in the model (see also, [32,38]). Table 4 presents the results for the in-sample and out-of-sample forecast evaluation using Clark and West (C-W) approach.

There are two panels in Table 3. The first panel presents the results for the stock returns predictability model based on news-based index of COVID-19-induced uncertainty. This is compared with the results for the stock returns predictability model based on 
our proposed news-macro composite index, presented in the second panel. The result shows that one period lag of stock returns is negative and statistically significant in both models. This implies that there is significant stock returns persistence. Hence, the dynamic model appears more appropriate for modeling the predictability of stock returns in these countries. In addition, the control variables (WTI oil price and exchange rate) considered are statistically significant. This implies that accounting for control variables improves the explanatory power of the predictive models.

Table 3. Predictability Result (Main Estimation).

\begin{tabular}{|c|c|c|c|c|}
\hline \multirow{2}{*}{ Variables } & \multicolumn{2}{|c|}{ Model without Control } & \multicolumn{2}{|c|}{ Model with Control } \\
\hline & Static & Dynamic & Static & Dynamic \\
\hline \multicolumn{5}{|c|}{ News-Based Index of COVID-Induced Uncertainty [ciustk $\left.{ }_{\text {news }}\right]$} \\
\hline $\operatorname{rstk}(-1)$ & - & $-0.128^{* * *}[0.040]$ & - & $-0.165^{* * *}[0.044]$ \\
\hline $\operatorname{lwti}(-1)$ & - & - & $-0.672^{* * *}[0.087]$ & $-0.609^{* * *}[0.097]$ \\
\hline $\operatorname{lexr}(-1)$ & - & - & $-0.189 *[0.115]$ & $0.056[0.131]$ \\
\hline lciustk $_{\text {news }}(-1)$ & $-1.060^{* * *[0.258]}$ & $-1.752 * * *[0.282]$ & $-1.204^{* * *}[0.257]$ & $-1.874^{* * *}[0.279]$ \\
\hline lciustk $_{\text {news }}(-2)$ & $0.003[0.396]$ & $0.598[0.379]$ & $0.175[0.404]$ & $0.659 *[0.363]$ \\
\hline lciustk $_{\text {news }}(-3)$ & $-1.593^{* * *}[0.262]$ & $-1.605^{* * *}[0.258]$ & $-1.762^{* * *}[0.267]$ & $-1.616^{* * *}[0.270]$ \\
\hline lciustk $_{\text {news }}(-4)$ & $2.181^{* * *}[0.465]$ & $1.797^{* * *}[0.396]$ & $2.261^{* * *}[0.456]$ & $1.776^{* * *}[0.363]$ \\
\hline lciustk $_{\text {news }}(-5)$ & $0.566^{* *}[0.281]$ & $1.050 * * *[0.212]$ & $0.463 *[0.275]$ & $0.996^{* * *}[0.207]$ \\
\hline Joint Coef. Est. & $0.096^{* * *}$ & $0.088^{* * *}$ & $-0.066^{* *}$ & $-0.059 * *$ \\
\hline \multicolumn{5}{|c|}{ Composite Index of COVID-Induced Uncertainty [ciustk $\left.k_{\text {comp }}\right]$} \\
\hline $\operatorname{rstk}(-1)$ & - & $-0.107^{* *}[0.043]$ & - & $-0.178^{* * *}[0.049]$ \\
\hline $\operatorname{lwti}(-1)$ & - & - & $0.747^{* * *}[0.160]$ & $0.980^{* * *}[0.197]$ \\
\hline $\operatorname{lexr}(-1)$ & - & - & $-0.282 *[0.170]$ & $-0.043[0.208]$ \\
\hline lciustk $_{\text {comp }}(-1)$ & $-2.141^{* * *}[0.334]$ & $-1.673^{* * *}[0.263]$ & $-2.222 * * *[0.355]$ & $-1.651^{* * *}[0.264]$ \\
\hline lciustk $_{\text {comp }}(-2)$ & $3.199 * * *[0.743]$ & $2.176^{* * *}[0.547]$ & $3.085^{* * *}[0.735]$ & $1.711^{* * *}[0.549]$ \\
\hline lciustk $_{\text {comp }}(-3)$ & $1.047[0.769]$ & $2.171^{* * *}[0.677]$ & $1.013[0.764]$ & $2.376^{* * *}[0.719]$ \\
\hline lciustk $_{\text {comp }}(-4)$ & $-5.317^{* * *}[0.777]$ & $-5.739 * * *[0.735]$ & $-5.821^{* * *}[0.777]$ & $-6.309 * * *[0.786]$ \\
\hline lciustk $_{\text {comp }}(-5)$ & $1.492^{* * *}[0.515]$ & $1.160^{* * *}[0.444]$ & $1.643^{* * *}[0.492]$ & $1.164^{* *}[0.463]$ \\
\hline Joint Coef. Est. & $-1.720^{* * *}$ & $-1.905^{* * *}$ & $-2.302^{* * *}$ & $-2.709^{* * *}$ \\
\hline
\end{tabular}

Note: Figures in [] are standard errors of the estimated parameters. ${ }^{* * *},{ }^{* *}$ and ${ }^{*}$ indicate statistical significance at $1 \%, 5 \%$ and $10 \%$ respectively.

Meanwhile the joint coefficient from the predictability model with our proposed composite COVID-19-induced uncertainty index (in the second panel) is also negative and significant, even without accounting for the role of domestic and foreign factors (control variables). This suggests that our proposed news-macro composite index is a better predictor for stock market returns than the news-based index. The significance of accounting for control variables is, however, visible in the size of the joint coefficient of the composite index, which would have been underestimated. The negative effect of the lagged COVID-19-induced uncertainty on the stock returns of selected countries suggests that high uncertainties during the COVID-19 era adversely affected the stock returns of the 20 worst-hit countries. This indicates that stock market investment cannot serve as a safe haven during the COVID-19 pandemic in these countries. Notably, the joint coefficient of uncertainty due to COVID-19 with our proposed news-macro composite index is higher than that of the news-based index. This suggests that ignoring the uncertainty associated with global and domestic macroeconomic factors in measuring uncertainty due to COVID19 would amount to underestimation of the COVID-19 effect.

The results of the Clark and West $(C-W)$ forecast evaluation of the in-sample and the 10-day, 20-day out-of-sample forecasts of the models are presented in Table 4 . This is considered with and without control variables, using 50\% and 75\% data samples. Basically, we compare the models with the news index and news-macro composite index against the historical average model in panels one and two of the table. This is to determine the 
relative forecast performance of the individual model against the historical average model. In the third panel, we compare both models to determine the superiority of the forecast performance of our proposed news-macro composite index over the news-based index. Notably, historical average was considered as the restricted model under panels one and two of Table 4, in which case the news index and news-macro composite index models are the unrestricted model under each respective panel. In the third panel, the news-based model is considered as the restricted model, while our proposed news-macro-compositeindex-based model is considered the unrestricted model. A positive and significant $\mathrm{CW}$ statistic implies that the unrestricted model outperforms the restricted model. Otherwise (if $\mathrm{CW}$ is negative and significant), the unrestricted model would be preferred.

Table 4. Clark and West Result for Forecast Evaluation (Main Estimation).

\begin{tabular}{|c|c|c|c|c|c|c|c|c|}
\hline \multirow{3}{*}{ Variables } & \multicolumn{4}{|c|}{ Model without Control } & \multicolumn{4}{|c|}{ Model with Control } \\
\hline & \multicolumn{2}{|c|}{$50 \%$ Sample } & \multicolumn{2}{|c|}{$75 \%$ Sample } & \multicolumn{2}{|c|}{$50 \%$ Sample } & \multicolumn{2}{|c|}{$75 \%$ Sample } \\
\hline & Static & Dynamic & Static & Dynamic & Static & Dynamic & Static & Dynamic \\
\hline \multicolumn{9}{|c|}{ Model with News-Based Index versus Historical Average Model } \\
\hline In-sample & $\begin{array}{c}1.926^{* * *} \\
{[0.359]}\end{array}$ & $\begin{array}{c}3.662 * * * \\
{[0.575]}\end{array}$ & $\begin{array}{c}1.205^{* * *} \\
{[0.218]}\end{array}$ & $\begin{array}{c}2.243^{* * *} \\
{[0.337]}\end{array}$ & $\begin{array}{c}3.063 * * * \\
{[0.416]}\end{array}$ & $\begin{array}{c}4.989 * * * \\
{[0.738]}\end{array}$ & $\begin{array}{l}1.854^{* * *} \\
{[0.246]}\end{array}$ & $\begin{array}{c}3.170 * * * \\
{[0.427]}\end{array}$ \\
\hline 10-Day ahead & $\begin{array}{c}1.635^{* * *} \\
{[0.315]}\end{array}$ & $\begin{array}{c}3.233^{* * *} \\
{[0.503]}\end{array}$ & $\begin{array}{c}1.185^{* * *} \\
{[0.200]}\end{array}$ & $\begin{array}{c}2.101^{* * * *} \\
{[0.308]}\end{array}$ & $\begin{array}{c}0.530 \\
{[0.902]}\end{array}$ & $\begin{array}{c}2.806^{* * *} \\
{[1.001]}\end{array}$ & $\begin{array}{c}0.911^{* * *} \\
{[0.346]}\end{array}$ & $\begin{array}{c}2.134^{* * *} \\
{[0.468]}\end{array}$ \\
\hline 20-Day ahead & $\begin{array}{c}1.516^{* * *} \\
{[0.280]}\end{array}$ & $\begin{array}{c}2.883 * * * \\
{[0.448]}\end{array}$ & $\begin{array}{c}1.095^{* * *} \\
{[0.184]}\end{array}$ & $\begin{array}{c}1.957^{* * *} \\
{[0.283]}\end{array}$ & $\begin{array}{c}-2.631^{* *} \\
{[1.330]}\end{array}$ & $\begin{array}{l}-0.104 \\
{[1.213]}\end{array}$ & $\begin{array}{l}0.767^{* *} \\
{[0.344]}\end{array}$ & $\begin{array}{c}1.909 * * * \\
{[0.448]}\end{array}$ \\
\hline \multicolumn{9}{|c|}{ Model with Composite Index versus Historical Average Model } \\
\hline In-sample & $\begin{array}{c}6.443^{* * *} \\
{[0.877]}\end{array}$ & $\begin{array}{c}8.344 * * * \\
{[1.017]}\end{array}$ & $\begin{array}{c}3.682 * * * \\
{[0.477]}\end{array}$ & $\begin{array}{l}4.618^{* * *} \\
{[0.548]}\end{array}$ & $\begin{array}{c}9.171 * * * \\
{[1.021]}\end{array}$ & $\begin{array}{c}12.768 * * * \\
{[1.358]}\end{array}$ & $\begin{array}{c}4.463 * * * \\
{[0.539]}\end{array}$ & $\begin{array}{c}5.922 * * * \\
{[0.674]}\end{array}$ \\
\hline 10-Day ahead & $\begin{array}{c}5.085^{* * *} \\
{[0.835]}\end{array}$ & $\begin{array}{c}6.703^{* * *} \\
{[0.966]}\end{array}$ & $\begin{array}{c}2.534^{* * *} \\
{[0.527]}\end{array}$ & $\begin{array}{c}3.236^{* * *} \\
{[0.599]}\end{array}$ & $\begin{array}{c}7.839 * * * \\
{[0.906]}\end{array}$ & $\begin{array}{c}11.131^{* * *} \\
{[1.202]}\end{array}$ & $\begin{array}{c}3.293 * * * \\
{[0.558]}\end{array}$ & $\begin{array}{c}4.475^{* * *} \\
{[0.683]}\end{array}$ \\
\hline 20-Day ahead & $\begin{array}{c}3.235^{* * * *} \\
{[0.831]}\end{array}$ & $\begin{array}{c}4.372 * * * \\
{[0.979]}\end{array}$ & $\begin{array}{c}2.152 * * * \\
{[0.503]}\end{array}$ & $\begin{array}{c}2.806^{* * *} \\
{[0.572]}\end{array}$ & $\begin{array}{c}6.418^{* * *} \\
{[0.811]}\end{array}$ & $\begin{array}{c}9.175^{* * *} \\
{[1.079]}\end{array}$ & $\begin{array}{c}2.848^{* * *} \\
{[0.526]}\end{array}$ & $\begin{array}{c}3.928^{* * *} \\
{[0.643]}\end{array}$ \\
\hline \multicolumn{9}{|c|}{ Model with Composite Index versus Model with News-Based Index } \\
\hline In-sample & $\begin{array}{c}5.549 * * * \\
{[0.783]}\end{array}$ & $\begin{array}{c}6.259 * * * \\
{[0.777]}\end{array}$ & $\begin{array}{c}6.692^{* * *} \\
{[0.817]}\end{array}$ & $\begin{array}{c}8.368^{* * *} \\
{[0.819]}\end{array}$ & $\begin{array}{c}3.025^{* * *} \\
{[0.441]}\end{array}$ & $\begin{array}{c}3.204^{* * *} \\
{[0.428]}\end{array}$ & $\begin{array}{c}3.461^{* * *} \\
{[0.475]}\end{array}$ & $\begin{array}{c}3.852 * * * \\
{[0.468]}\end{array}$ \\
\hline 10-Day ahead & $\begin{array}{c}6.191 * * * \\
{[0.800]}\end{array}$ & $\begin{array}{c}6.830 * * * \\
{[0.822]}\end{array}$ & $\begin{array}{c}146.105^{* * *} \\
{[13.899]}\end{array}$ & $\begin{array}{c}112.957 * * * \\
{[11.609]}\end{array}$ & $\begin{array}{c}2.764^{* * * *} \\
{[0.505]}\end{array}$ & $\begin{array}{c}2.776^{* * *} \\
{[0.520]}\end{array}$ & $\begin{array}{c}5.109^{* * * *} \\
{[0.721]}\end{array}$ & $\begin{array}{l}4.477^{* * *} \\
{[0.739]}\end{array}$ \\
\hline 20-Day ahead & $\begin{array}{c}5.674^{* * *} \\
{[0.813]}\end{array}$ & $\begin{array}{c}6.021^{* * *} \\
{[0.895]}\end{array}$ & $\begin{array}{c}250.103^{* * *} \\
{[16.158]}\end{array}$ & $\begin{array}{c}187.254^{* * *} \\
{[13.409]}\end{array}$ & $\begin{array}{c}3.022 * * * \\
{[0.487]}\end{array}$ & $\begin{array}{c}3.033^{* * *} \\
{[0.506]}\end{array}$ & $\begin{array}{c}6.670 * * * \\
{[0.820]}\end{array}$ & $\begin{array}{c}5.203 * * * \\
{[0.841]}\end{array}$ \\
\hline
\end{tabular}

Note: Figures in [] are the associated standard errors of the estimated Clark and West statistic. ${ }^{* * *}$ indicates statistical significance at $1 \%$ level. Positive and significant Clark and West statistics indicate preference of the first model in each of the model pairs, while a significantly negative value indicates preference of the second model over the first model in the corresponding model pairs.

As evident from the first panel of Table 4, the CW statistic for the in-sample forecast is consistently positive and significant across all models; static and dynamic, with and without control variables, over the 50 percent and 75 percent data samples. This suggests that the predictive model with the news-based COVID-19 uncertainty index has better in-sample forecast performance than the historical average model. This result is also consistent over the 10-day-ahead out-of-sample forecasts. The historical average model, however, outperforms the dynamic model with control variables over the 20-day-ahead forecast when $50 \%$ of the data sample is used. This suggests that forecast performance of the news-based COVID-19 uncertainty index may be inconsistent over a long forecast period. Comparing this with the model with a news-macro composite index (in the second panel of Table 4), the C-W coefficients are positive and significant for the in-sample and the 10-day and 20-day out-of-sample period forecast. This suggests that our proposed news-macro composite index has better in-sample and out-of-sample stock returns forecast performance than the news-based index. This is additionally confirmed in the third panel of Table 4, where the coefficients of $\mathrm{C}-\mathrm{W}$ are positive and significant in the in-sample 
and over the 10-day and 20-day ahead out-of-sample forecast horizons. The result is also consistent over the $50 \%$ and $75 \%$ sample sizes.

\subsection{Robustness}

For robustness purposes, we compare the predictability and forecast performance of the stock returns when predicted with our proposed news-macro composite index compared to those predicted with the alternative uncertainty index, that is, the Chicago Board Options Exchange (CBOE) volatility index (VIX). The results of the predictability and forecast evaluation of the predictive model with VIX are presented in Tables 5 and 6, respectively. As is evident from Table 5, the lagged stock returns in the dynamic models have negative and statistically significant coefficients, which indicates the persistence of negative stock returns. This is consistent with the result obtained from both news-based and news-macro composite predictability models (Section 3.2). Similarly, the joint significance of the coefficients of VIX is negative and statistically significant under the model with and without control variables. Since the result is relatively inefficient under the news-based model (without control variables), this suggests that VIX is a better predictor of stock returns compared to the news-based COVID-19 uncertainty index.

Table 5. Predictability result for volatility index (VIX)-based models.

\begin{tabular}{|c|c|c|c|c|}
\hline \multirow{2}{*}{ Variables } & \multicolumn{2}{|c|}{ Model without Control } & \multicolumn{2}{|c|}{ Model with Control } \\
\hline & Static & Dynamic & Static & Dynamic \\
\hline $\operatorname{rstk}(-1)$ & - & $-0.178^{* * *}[0.043]$ & - & $-0.206^{* * *}[0.043]$ \\
\hline $\operatorname{lwti}(-1)$ & - & - & $-1.297^{* * *}[0.121]$ & $-1.236^{* * *}[0.132]$ \\
\hline $\operatorname{lexr}(-1)$ & - & - & -16.956 [13.099] & $5.727[14.532]$ \\
\hline $\operatorname{lvix}(-1)$ & $-1.078[0.807]$ & $-3.878^{* * *}[0.736]$ & $-0.401[0.867]$ & $-3.125^{* * *}[0.764]$ \\
\hline $\operatorname{lvix}(-2)$ & $-4.535^{* * *}[1.300]$ & $-2.284^{* *}[1.139]$ & $-5.380^{* * *}[1.406]$ & $-3.306^{* * *}[1.171]$ \\
\hline $\operatorname{lvix}(-3)$ & $2.561 * * *[0.642]$ & $2.328 * * *[0.688]$ & $2.968^{* * *}[0.683]$ & $2.895^{* * *}[0.689]$ \\
\hline $\operatorname{lvix}(-4)$ & $2.388 * * *[0.516]$ & $2.923 * * *[0.548]$ & $2.302 * * *[0.496]$ & $2.839 * * *[0.546]$ \\
\hline $\operatorname{lvix}(-5)$ & $0.568[0.409]$ & $0.713 *[0.397]$ & $-0.341[0.407]$ & $-0.213[0.422]$ \\
\hline Joint Coef. Est. & $-0.096 *$ & $-0.198 * * *$ & $-0.852 * * *$ & $-0.910 * * *$ \\
\hline
\end{tabular}

Note: Figures in [] are standard errors of the estimated parameters. ${ }^{* * *},{ }^{* *}$ and ${ }^{*}$ indicate statistical significance at $1 \%, 5 \%$ and $10 \%$, respectively.

Table 6. Clark and West Result Forecast Evaluation (Volatility Index).

\begin{tabular}{|c|c|c|c|c|c|c|c|c|}
\hline \multirow{2}{*}{ Variables } & \multicolumn{4}{|c|}{ Model without Control } & \multicolumn{4}{|c|}{ Model with Control } \\
\hline & \multicolumn{2}{|c|}{ Static } & \multicolumn{2}{|c|}{ Dynamic } & \multicolumn{2}{|c|}{ Static } & \multicolumn{2}{|c|}{ Dynamic } \\
\hline \multicolumn{9}{|c|}{ Model with Volatility Index [VIX] vs Historical Average Model } \\
\hline & $\begin{array}{c}50 \% \\
\text { Sample }\end{array}$ & $\begin{array}{c}75 \% \\
\text { Sample }\end{array}$ & $\begin{array}{c}50 \% \\
\text { Sample }\end{array}$ & $\begin{array}{c}75 \% \\
\text { Sample }\end{array}$ & $\begin{array}{c}50 \% \\
\text { Sample }\end{array}$ & $\begin{array}{c}75 \% \\
\text { Sample }\end{array}$ & $\begin{array}{c}50 \% \\
\text { Sample }\end{array}$ & $\begin{array}{c}75 \% \\
\text { Sample }\end{array}$ \\
\hline In-sample & $\begin{array}{c}3.472^{* * *} \\
{[0.468]}\end{array}$ & $\begin{array}{c}1.998^{* * *} \\
{[0.264]}\end{array}$ & $\begin{array}{c}4.619^{* * *} \\
{[0.603]}\end{array}$ & $\begin{array}{c}2.938^{* * *} \\
{[0.349]}\end{array}$ & $\begin{array}{c}5.071^{* * *} \\
{[0.606]}\end{array}$ & $\begin{array}{c}2.863^{* * *} \\
{[0.331]}\end{array}$ & $\begin{array}{c}6.321^{* * *} \\
{[0.792]}\end{array}$ & $\begin{array}{c}3.945^{* * *} \\
{[0.457]}\end{array}$ \\
\hline 10-Day ahead & $\begin{array}{c}2.892^{* * *} \\
{[0.411]}\end{array}$ & $\begin{array}{c}1.848^{* * *} \\
{[0.243]}\end{array}$ & $\begin{array}{c}3.962 * * * \\
{[0.531]}\end{array}$ & $\begin{array}{c}2.637^{* * *} \\
{[0.321]}\end{array}$ & $\begin{array}{c}1.313 \\
{[1.145]}\end{array}$ & $\begin{array}{c}1.531^{* * *} \\
{[0.497]}\end{array}$ & $\begin{array}{l}2.679 * * \\
{[1.205]}\end{array}$ & $\begin{array}{c}2.488^{* * *} \\
{[0.583]}\end{array}$ \\
\hline 20-Day ahead & $\begin{array}{c}2.657^{* * *} \\
{[0.368]}\end{array}$ & $\begin{array}{c}1.705^{* * *} \\
{[0.225]}\end{array}$ & $\begin{array}{c}3.590^{* * *} \\
{[0.474]}\end{array}$ & $\begin{array}{c}2.439 * * * \\
{[0.296]}\end{array}$ & $\begin{array}{c}-3.116^{*} \\
{[1.607]}\end{array}$ & $\begin{array}{c}1.312 \text { *** } \\
{[0.497]}\end{array}$ & $\begin{array}{l}-1.616 \\
{[1.567]}\end{array}$ & $\begin{array}{c}2.213^{* * *} \\
{[0.570]}\end{array}$ \\
\hline \multicolumn{9}{|c|}{ Model with Composite Index vs Model with Volatility Index [VIX] } \\
\hline In-Sample & $\begin{array}{c}5.122 * * * \\
{[0.724]}\end{array}$ & $\begin{array}{c}5.627 * * * \\
{[0.634]}\end{array}$ & $\begin{array}{c}5.656^{* * *} \\
{[0.744]}\end{array}$ & $\begin{array}{c}6.750^{* * * *} \\
{[0.667]}\end{array}$ & $\begin{array}{c}2.947^{* * * *} \\
{[0.414]}\end{array}$ & $\begin{array}{c}3.125^{* * *} \\
{[0.369]}\end{array}$ & $\begin{array}{c}3.332 * * * \\
{[0.469]}\end{array}$ & $\begin{array}{c}3.645^{* * *} \\
{[0.431]}\end{array}$ \\
\hline 10-Day & $\begin{array}{c}5.014^{* * *} \\
{[0.760]}\end{array}$ & $\begin{array}{c}4.557 * * * \\
{[0.744]}\end{array}$ & $\begin{array}{c}247.446^{* * *} \\
{[22.417]}\end{array}$ & $\begin{array}{c}228.908^{* * *} \\
{[21.530]}\end{array}$ & $\begin{array}{c}2.054^{* * *} \\
{[0.479]}\end{array}$ & $\begin{array}{c}1.419^{* * *} \\
{[0.469]}\end{array}$ & $\begin{array}{c}12.116^{* * *} \\
{[1.508]}\end{array}$ & $\begin{array}{c}11.503^{* * *} \\
{[1.520]}\end{array}$ \\
\hline 20-Day & $\begin{array}{c}4.429 * * * \\
{[0.775]}\end{array}$ & $\begin{array}{c}3.180 * * * \\
{[0.816]}\end{array}$ & $\begin{array}{c}426.808^{* * *} \\
{[26.156]}\end{array}$ & $\begin{array}{c}388.680 * * * \\
{[25.061]}\end{array}$ & $\begin{array}{c}1.787 * * * \\
{[0.468]}\end{array}$ & $\begin{array}{c}0.736 \\
{[0.466]}\end{array}$ & $\begin{array}{c}20.609 * * * \\
{[1.948]}\end{array}$ & $\begin{array}{c}18.864^{* * *} \\
{[1.940]}\end{array}$ \\
\hline
\end{tabular}

Note: Figures in [] are the associated standard errors of the estimated Clark and West statistic. ${ }^{* * *}$ indicates statistical significance at $1 \%$ level. Positive and significant Clark and West statistics indicate preference of the first model in each of the model pairs, while a significantly negative value indicates preference of the second model over the first model in the corresponding model pairs. 
The forecast evaluation result for the VIX-based stock returns predictive model is presented in Table 6. The model is compared with the history average model and our proposed news-macro-based model. In comparison with the historical average model, the result shows that the VIX-based predictive model outperforms the historical average model in-sample and out-of-sample, without accounting for the role of control variables. However, after accounting for the role of control variables, it only outperforms the historical average model in-sample and over the 10-day ahead horizon. This is similar to the results obtained from the forecast evaluation of the news-based model, suggesting that the forecast performance of VIX is similar to that of the news-based uncertainty due to COVID-19. Since the forecast performance of these two indexes is similar, this suggests that our proposed (news-macro) composite index will outperform the VIX index, as it outperformed the newsbased uncertainty index in predicting the stock returns of the top 20 worst-hit countries by COVID-19. This supposition is justified by the CW coefficients for the comparison of the composite index with the VIX index. As is evident from the second panel of Table 6, the C-W coefficients are positive and statistically significant, both with and without control variables, and over the short-term (10-day) and medium-term (20-day) forecast periods. This implies that our proposed (news-macro) composite index outperforms news-based indexes and the (CBOE) volatility index (VIX) as a measure of uncertainty due to COVID-19. This result is robust to the choice of model (static or dynamic), sample size (50\% or $75 \%$ ) and out-of-sample period (10-day- or 20-day-ahead forecast).

Having confirmed the outperformance of our predictive model that incorporates the newly developed composite index of uncertainty over the variant that incorporates VIX, we further compare our predictive model with the conventional pooled ordinary least squares model, which both incorporate the new index of uncertainty as a predictor (see Tables 7 and 8). The comparison is basically used to ascertain the importance of accounting for the heterogeneity across the different stocks. The POLS estimates of the joint coefficients of the composite index are negative and statistically significant (Table 7). This feat is similar to the estimates from our predictive model with the composite index, regardless of the model structure (static/dynamic with and without control variables). However, the in-sample and out-of-sample forecasts of the POLS model under-perform compared to our predictive model across the different sample compositions and forecast horizons (Table 8). The stance of outperformance is not sensitive to the choice of model (static or dynamic), sample size (50\% or 75\%) and out-of-sample period (10-day- or 20-day-ahead forecast). This clearly indicates that, accounting for heterogeneity, whenever it exists, does improve forecast performance.

Table 7. Predictability result for Pooled Ordinary Least Squares (POLS) models.

\begin{tabular}{|c|c|c|c|c|}
\hline \multirow{2}{*}{ Variables } & \multicolumn{2}{|c|}{ Model without Control } & \multicolumn{2}{|c|}{ Model with Control } \\
\hline & Static & Dynamic & Static & Dynamic \\
\hline $\operatorname{rstk}(-1)$ & - & $-0.115^{* * *}[0.020]$ & - & $-0.174 * * *[0.021]$ \\
\hline lwti(-1) & - & - & $0.742^{* * *}[0.192]$ & $0.977^{* * *}[0.192]$ \\
\hline $\operatorname{lexr}(-1)$ & - & - & $0.160 * *[0.068]$ & $0.357^{* * *}[0.071]$ \\
\hline lciustk $_{\text {comp }}(-1)$ & $-2.141^{* * *}[0.329]$ & $-1.698^{* * *}[0.336]$ & $-2.236^{* * *}[0.328]$ & $-1.688^{* * *}[0.331]$ \\
\hline lciustk $_{\text {comp }}(-2)$ & $3.199 * * *[0.601]$ & $2.390 * * *[0.614]$ & $2.831 * * *[0.596]$ & $1.603 * * *[0.608]$ \\
\hline lciustk $_{\text {comp }}(-3)$ & $1.047[0.698]$ & $1.677^{* *}[0.702]$ & $1.364 * *[0.693]$ & $2.262 * * *[0.693]$ \\
\hline lciustk $_{\text {comp }}(-4)$ & $-5.317^{* * *}[0.661]$ & $-5.322 * * *[0.657]$ & $-6.007^{* * *}[0.659]$ & $-6.073^{* * *}[0.650]$ \\
\hline lciustk $_{\text {comp }}(-5)$ & $1.492^{* * *}[0.390]$ & $1.061^{* * *}[0.395]$ & $1.744^{* * *}[0.388]$ & $1.195^{* * *}[0.389]$ \\
\hline Joint Coef. Est. & $-1.720^{* * *}$ & $-1.892 * * *$ & $-2.304^{* * *}$ & $-2.702 * * *$ \\
\hline
\end{tabular}

Note: Figures in [] are standard errors of the estimated parameters. ${ }^{* * *},{ }^{* *}$ and ${ }^{*}$ indicate statistical significance at $1 \%, 5 \%$ and $10 \%$, respectively. 
Table 8. Clark and West Result Forecast Evaluation (POLS Model).

\begin{tabular}{|c|c|c|c|c|c|c|c|c|}
\hline \multirow{2}{*}{ Variables } & \multicolumn{4}{|c|}{ Model without Control } & \multicolumn{4}{|c|}{ Model with Control } \\
\hline & \multicolumn{2}{|c|}{ Static } & \multicolumn{2}{|c|}{ Dynamic } & \multicolumn{2}{|c|}{ Static } & \multicolumn{2}{|c|}{ Dynamic } \\
\hline \multicolumn{9}{|c|}{ Our Predictive Model with Composite Index vs POLS Model with Composite Index } \\
\hline & $50 \%$ & $75 \%$ & $50 \%$ & $75 \%$ & $50 \%$ & $75 \%$ & $50 \%$ & $75 \%$ \\
\hline & Sample & Sample & Sample & Sample & Sample & Sample & Sample & Sample \\
\hline \multirow{2}{*}{ In-Sample } & $2.213^{* * *}$ & $3.410 * * *$ & $1.278^{* * *}$ & $1.911^{* * *}$ & $3.057 * * *$ & $4.768^{* * *}$ & $1.675^{* * *}$ & $2.588^{* * *}$ \\
\hline & [0.397] & [0.541] & {$[0.225]$} & [0.301] & [0.449] & {$[0.643]$} & {$[0.253]$} & [0.361] \\
\hline \multirow{2}{*}{ 10-Day } & $4.462 * * *$ & $6.618 * * *$ & 0.404 & 0.779 * & $3.978 * * *$ & $6.400 * * *$ & $0.979^{* * *}$ & $1.693 * * *$ \\
\hline & {$[0.594]$} & [0.737] & {$[0.358]$} & [0.434] & [0.463] & [0.669] & {$[0.351]$} & {$[0.450]$} \\
\hline \multirow{2}{*}{ 20-Day } & $3.735^{* * *}$ & $5.627^{* * *}$ & 0.389 & 0.713 & $5.437^{* * *}$ & $9.111^{* * *}$ & $1.138^{* * *}$ & $1.835^{* * *}$ \\
\hline & {$[0.656]$} & {$[0.821]$} & {$[0.361]$} & $*[0.431]$ & [0.496] & {$[0.761]$} & {$[0.351]$} & {$[0.441]$} \\
\hline
\end{tabular}

Note: Figures in [] are the associated standard errors of the estimated Clark and West statistic. ${ }^{* * *}$ indicates statistical significance at $1 \%$ level. Positive and significant Clark and West statistics indicate preference of the first model in each of the model pairs, while a significantly negative value indicates preference of the second model over the first model in the corresponding model pairs.

\section{Discussion}

As evident from the first panel of Table 3, the joint coefficient of COVID-19-induced uncertainty is positive without accounting for the role of control variables. This indicates that failure to account for the role of domestic and foreign factors (control variables) in the model may lead to inefficient results. This is consistent with the findings of [38], which find that macroeconomic variables play an important role in explaining the US stock returns. The negative relationship between oil price and stock market returns has usually been explained from the perspective of higher costs and lower cash flows to the firm, which will eventually cause lower returns on investments, including stock returns [32]. Nonetheless, the joint coefficient of the news-based index as a predictor of stock returns implies that a news-based measure of uncertainty is a good predictor of stock returns. This confirms results from earlier studies, such as [19,25-27].

\section{Conclusions}

This study is an intellectual contribution to the extant literature that have measured uncertainty due to the COVID-19 pandemic, and improves upon this literature by proposing a new index for measuring the uncertainty due to the pandemic, given the implications of the pandemic for financial markets and investors. The contribution of the study lies in its presentation of a more informative composite index comprising a news-based index (containing Google trends of COVID-19-related news) and the macro-based index (which relates to uncertainties due to global economic indicators, namely, global oil price, gold price, stock price, commodity prices and exchange rate). The study obtained the newsbased index using a principal component analysis of Google trends of COVID-19-related searches as a measure of COVID-19-induced uncertainty. It also obtained the macro-based index by extracting the inherent volatilities (from the optimal among seven competing stochastic volatility models) in the five global macro-variables that are closely linked to equity markets, as highlighted earlier, and then combined them into a single macro-based index of uncertainty using the dynamic factor model. The composite index was subsequently computed by combining the scaled news-based and macro-based indexes, using the conventional principal component analysis.

The study covers the period between 1 January 2020 and 21 July 2020, covering the period the news about the Coronavirus disease hit the global news space, and also includes its subsequent declaration as a pandemic on 11th March 2020; a date at which we observed a structural shift in the stock series of the worst-hit countries through descriptive analyses. The preliminary discussion also reveals that the composite- and macro-based indexes closely aligned with the stock prices of the countries, further justifying the contribution of this study to improving the news-based predictive model with relevant macroeconomic information. To evaluate the performance of our proposed index in comparison with other indexes, we applied the composite uncertainty index due to the COVID-19 pandemic to 
the stock returns' predictability of the top twenty worst-hit economies, with the aid of competing static and dynamic panel estimators with common-correlated effects, following the approaches of $[30,39,40]$. As an attempt at robustness, we further compared the predictability of the proposed composite index developed in this study against the popular news-based index of the Chicago Board Options Exchange (CBOE) volatility index (VIX), as well as the conventional pooled ordinary least-squares regression model, which ignores the heterogeneity of the intercept and slope.

We obtained a number of interesting key findings. One, the dynamic model is more appropriate for modelling the stock returns of these countries, and the addition of macroeconomic variables improves the predictive power of the models. Two, the proposed news-macro composite index turned out to be a better predictor of stock returns than the news-based measure of COVID-19 uncertainty. This was established for both in-sample and out-of-sample forecast performances. Our results are consistent with findings from extant studies [19,39-41]. Three, the section on robustness showed similar forecast performances between the news-based uncertainty index and the widely used news-based Chicago Board Options Exchange (CBOE) volatility index. However, our proposed newsmacro composite index also outperformed the CBOE volatility index, regardless of the choice of model (whether static or dynamic), sample size considered ( $50 \%$ or $75 \%$ ), and the forecast horizon (10-day- or 20-day-ahead out-of-sample forecast). It also outperformed the pooled ordinary least-squares regression model, hence indicating the relevance of accounting for heterogeneity. Ultimately, we conclude that neglecting the uncertainty information associated with macroeconomic factors in the modelling downplays the effect of the COVID-19 pandemic.

Author Contributions: Conceptualization; A.E.O. and A.A.S., Methodology; A.E.O. and A.A.S., Validation: A.A.S., Formal analysis; A.E.O. and T.F.O., Investigation; T.F.O. and I.A.A., Resources; A.E.O., T.F.O. and I.A.A., Data curation; A.E.O., T.F.O. and I.A.A., Writing-Original draft preparation; A.E.O., T.F.O. and I.A.A., Writing-Review and Editing; A.E.O., T.F.O. and I.A.A., Visualization; A.E.O., Supervision; A.A.S. All authors have read and agreed to the published version of the manuscript.

Funding: This research received no external funding.

Institutional Review Board Statement: Not relevant.

Informed Consent Statement: Not applicable.

Data Availability Statement: The data presented in this study are openly available in Open Science Framework at https: / mfr.osf.io/render?url=https $\% 3 \mathrm{~A} \% 2 \mathrm{~F} \% 2 \mathrm{Fosf} .10 \% 2 \mathrm{Fqnr} 4 \mathrm{k} \% 2 \mathrm{Fdownload}$ (accessed on 13 March 2021).

Conflicts of Interest: The authors declare no conflict of interest.

\section{References}

1. Baker, S.R.; Bloom, M.A.; Davis, S.J.; Terry, S.J. Covid-Induced Economic Uncertainty; Working Paper No. 26983; NBER: Cambridge, MA, USA, 2020.

2. Nicomedes, C.J.C.; Avila, R.M.A. An Analysis on the Panic during COVID-19 Pandemic through an Online Form. J. Aff. Dis. 2020. [CrossRef]

3. Salisu, A.A.; Akanni, L. Constructing a global fear index for COVID-19 pandemic. Emer. Mark. Fin. Trade 2020, 56, 2213-2230. [CrossRef]

4. Al-Awadhi, A.M.; Al-Saifi, K.; Al-Awadhi, A.; Alhamadi, S. Death and contagious infectious diseases: Impact of the COVID-19 virus on stock market returns. J. Beh. Exp. Fin. 2020, 100326. [CrossRef] [PubMed]

5. Albulescu, C.T. COVID-19 and the United States financial markets' volatility. Fin. Res. Let. 2020, 101699. [CrossRef]

6. Ashraf, B.N. Stock markets' reaction to COVID-19: Cases or fatalities? Res. Int. Bus. Fin. 2020, 54, 101249, 101016/jribaf2020101249. [CrossRef]

7. Baker, S.; Bloom, N.; Davis, S.J.; Kost, K.; Sammon, M.; Viratyosin, T. The Unprecedented Stock Market Reaction to COVID-19. Rev. Asset Pricing Stud. 2020, 10, 742-758. [CrossRef]

8. Ciner, C. Stock Return Predictability in the time of COVID-19. Fin. Res. Let. 2020. [CrossRef] 
9. Dutta, A.; Das, D.; Jana, R.K.; Vo, X.V. COVID-19 and oil market crash: Revisiting the safe haven property of gold and Bitcoin. Res. Pol. 2020, 69. [CrossRef]

10. Erdem, O. Freedom and Stock Market Performance during Covid-19 Outbreak. Fin. Res. Let. 2020, 101671. [CrossRef] [PubMed]

11. Haroon, O.; Rizvi, S. COVID-19: Media coverage and financial markets behavior-A sectoral inquiry. J. Beh. Exp. Fin. 2020, 27. [CrossRef] [PubMed]

12. He, P.; Sun, Y.; Zhang, Y.; Li, T. COVID-19's impact on stock prices across different sectors-An event study based on the Chinese stock market. Emer. Mark. Fin. Trade 2020, 56, 2198-2212. [CrossRef]

13. Lahmiri, S.; Bekiros, S. The Impact of COVID-19 pandemic upon Stability and Sequential Irregularity of Equity and Cryptocurrency Markets. Chaos Solitons Fractals 2020, 138, 109936. [CrossRef] [PubMed]

14. Mishra, A.; Rath, B.; Dash, A. Does the Indian financial market nosedive because of the COVID-19 outbreak, in comparison to after demonetisation and the GST? Emer. Mark. Fin. Trade 2020, 56, 2162-2180. [CrossRef]

15. Okorie, D.I.; Lin, B. Stock Markets and the COVID-19 Fractal Contagion Effects. Fin. Res. Let. 2020, 101640. [CrossRef] [PubMed]

16. Phan, D.; Narayan, P. Country responses and the reaction of the stock market to COVID-19-A Preliminary Exposition. Emer. Mark. Fin. Trade 2020, 56, 2138-2150. [CrossRef]

17. Salisu, A.A.; Ogbonna, A.; Adediran, I. Stock-induced Google trends and the predictability of sectoral stock returns. J. Forecast. 2020. [CrossRef]

18. Salisu, A.A.; Ogbonna, A.E.; Adewuyi, A. Google trends and the predictability of precious metals. Res. Pol. 2020, 65, 101542. [CrossRef]

19. Salisu, A.A.; Vo, X.V. Predicting stock returns in the presence of COVID-19 pandemic: The role of health news. Int. Rev. Fin. Ana. 2020, 71, 101546. [CrossRef]

20. Topcu, M.; Gulal, O.S. The impact of COVID-19 on emerging stock markets. Fin. Res. Let. 2020, 101691. [CrossRef]

21. Zhang, D.; Hu, M.; Ji, Q. Financial markets under the global pandemic of COVID 19. Fin. Res. Let. 2020, 36. [CrossRef] [PubMed]

22. Olubusoye, O.E.; Ogbonna, A.E.; Yaya, O.S.; Umolo, D. An Information-Based Index of Uncertainty and the predictability of Energy Prices. Int. J. Ener. Res. 2020. [CrossRef]

23. Salisu, A.A.; Adediran, I. Uncertainty due to infectious diseases and energy market volatility. Ener. Res. Let. 2020, 1. [CrossRef]

24. Prabheesh, K.; Padhan, R.; Garg, B. COVID-19 and the oil price-stock market nexus: Evidence from net oil-importing countries. Ener. Res. Let. 2020, 1. [CrossRef]

25. Zhao, R. Inferring private information from online news and searches: Correlation and prediction in Chinese stock market. Phys. A Stat. Mech. App. 2019, 528, 121450. [CrossRef]

26. Nguyen, C.P.; Schonckus, C.; Hong Nguyen, T.V. Google Search and Stock returns in Emerging Markets. Borsa Istanb. Rev. 2019, 19, 288-296. [CrossRef]

27. Chronopoulos, D.K.; Papadimitriou, F.I.; Vlastakis, N. Information demand and stock return predictability. J. Int. Money Fin. 2018, 80, 59-74. [CrossRef]

28. Salisu, A.A.; Swaray, R.; Oloko, T.F. Improving the predictability of the oil-US stock nexus: The role of macroeconomic variables. Econ. Model. 2019, 76, 153-171. [CrossRef]

29. Yaya, O.S.; Ogbonna, A.E. Do We Experience Day-of-the-Week Effects in Returns and Volatility of Cryptocurrency? MPRA Paper 91429; University Library of Munich: Munich, Germany, 2019.

30. Westerlund, J.; Karabiyik, H.; Narayan, P. Testing for predictability in panels with general Predictors. J. App. Econom. 2016. [CrossRef]

31. Clark, T.; West, T.D. Approximately normal tests for equal predictive accuracy in nested models. J. Econom. 2007, 138, 291-311. [CrossRef]

32. Salisu, A.A.; Oloko, T.F. Modeling oil price-US stock nexus: A VARMA-BEKK-AGARCH approach. Ener. Econs. 2015, 50, 1-12. [CrossRef]

33. Lakonishok, J.; Shapiro, A.C. Systematic risk, total risk and size as determinants of stock market returns. J. Bank. Fin. 1986, 10, 115-132. [CrossRef]

34. Gatfaoui, H. How Does Systematic Risk Impact Stocks? A Study of the French Financial Market. In Asset Allocation and International Investments; Gregoriou, G.N., Ed.; Chapter 10; Palgrave Macmillan, a division of Macmillan Publishers Limited: London, UK, 2007; pp. 183-213.

35. Santis, R.A.D. Unobservable Systematic Risk, Economic Activity and Stock Market. J. Bank. Fin. 2018, 97, 51-69. [CrossRef]

36. Chan, J.; Grant, A. Modeling energy price dynamics: GARCH versus stochastic volatility. Ener. Econs. 2016, 54, 182-189. [CrossRef]

37. Investing.com Website. 2020. Available online: https://www.investing.com (accessed on 13 March 2021).

38. Salisu, A.A.; Ogbonna, A.E.; Omosebi, P.A. Does the Choice of Estimator Matter for Forecasting? A Revisit; Centre for Econometric and Allied Research, University of Ibadan Working Papers Series, CWPS 0053; CEAR, Univeristy of Ibadan: Oyo, Nigeria, 2018.

39. Chudik, A.; Pesaran, M.H. Common correlated effects estimation of heterogeneous dynamic panel data models with weakly exogenous regressors. J. Econom. 2015, 188, 393-420. [CrossRef]

40. Chudik, A.; Mohaddes, K.; Pesaran, M.; Raissi, M. Long-Run Effects in Large Heterogeneous Panel Data Models with Cross-Sectionally Correlated Errors; Emerald Group Publishing Limited: Bingley, UK, 2016; pp. 85-135. 
41. Westerlund, J.; Narayan, P. Testing for predictability in panels of any time series dimension. Int. J. Forecast. 2016, 32, $1162-1177$. [CrossRef]

42. Ditzen, J. Estimating Dynamic Common Correlated Effects in Stata. Stata J. 2018, 18, 585-617. [CrossRef]

43. Ditzen, J. Estimating Long Run Effects in Models with Cross-Sectional Dependence Using Xtdcce2; CEERP Working Paper Series: 7; Heriot-Watt University: Edinburg, Scotland, 2019.

44. Zhang, J.; Lai, Y.; Lin, J. The day-of-the-Week effects of stock markets in different countries. Fin. Res. Let. 2017, 20, 47-62. [CrossRef]

45. Campbell, J.; Thompson, S. Predicting excess stock returns out of sample: Can anything beat the historical average? Rev. Fin. Stud. 2008, 21, 1509-1531. [CrossRef] 